
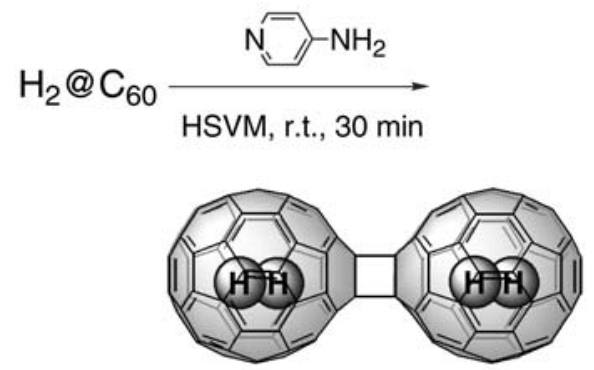

$30 \% \quad\left(\mathrm{H}_{2} @ \mathrm{C}_{60}\right)_{2}$

Fig. 4. Mechanochemical solid-state dimerization of $\mathrm{H}_{2} @ \mathrm{C}_{60}$ by the use of a high-speed vibration milling (HSVM) technique.

observed and predicted isotope distribution patterns in the MALDI-TOF mass spectrum (Fig. 3, C and D), in addition to correct elemental analysis for hydrogen (calculated for $\mathrm{C}_{60} \mathrm{H}_{2}: \mathrm{C}, 99.72$, and $\mathrm{H}, 0.28 \%$; found: C, 99.04 , and $\mathrm{H}, 0.24 \%$ ).

The very small downfield shift $(0.078 \mathrm{ppm})$ observed for the ${ }^{13} \mathrm{C}$ NMR signal of $\mathrm{H}_{2} @ \mathrm{C}_{60}$ (as compared to empty $\mathrm{C}_{60}$ ) indicates that the electronic property of the fullerene cage is largely unaffected by the encapsulation of $\mathrm{H}_{2}$. The ultraviolet-visible and infrared spectra of $\mathrm{H}_{2} @ \mathrm{C}_{60}$ are also exactly the same as those of empty $\mathrm{C}_{60}$. This situation contrasts with the cases of $\mathrm{Kr} @ \mathrm{C}_{60}(13)$ and $\mathrm{Xe} @ \mathrm{C}_{60}(12)$, in which larger downfield shifts are observed (0.39 ppm and 0.95 ppm, respectively), caused by appreciable electronic and van der Waals interactions between the $\mathrm{C}_{60}$ cage and the encapsulated atoms, which are much larger than $\mathrm{H}_{2}$.

The ${ }^{1} \mathrm{H}$ NMR signal for the encapsulated hydrogen of $\mathrm{H}_{2} @ \mathrm{C}_{60}$ in $o$-dichlorobenzene$d_{4}$ was observed at $\delta=-1.44 \mathrm{ppm}$, which is $5.98 \mathrm{ppm}$ upfield-shifted relative to the signal of dissolved free hydrogen. The extent of this upfield shift is comparable to that observed for ${ }^{3} \mathrm{He} @ \mathrm{C}_{60}(6.36$ ppm $)(9,10)$ in ${ }^{3} \mathrm{He}$ NMR relative to free ${ }^{3} \mathrm{He}$. This result shows that the shielding effect of total ring currents of the $\mathrm{C}_{60}$ cage is nearly the same, regardless of the paramagnetic species inside the cage.

The irrelevance of the encapsulated $\mathrm{H}_{2}$ to the electronic character of the outer cage was also demonstrated by cyclic voltammetry (0.5 mM in $o$-dichlorobenzene with $0.05 \mathrm{M}$ $\mathrm{Bu}_{4} \mathrm{NBF}_{4}$ for reduction and $0.5 \mathrm{mM}$ in 1,1,2,2-tetrachloroethane with $0.1 \mathrm{M} \mathrm{Bu}_{4} \mathrm{NPF}_{6}$ for oxidation). The voltammogram of $\mathrm{H}_{2} @ \mathrm{C}_{60}$ exhibited four reversible reduction waves and one irreversible oxidation peak at the same potentials as $\mathrm{C}_{60}$, within an experimental error of $\pm 0.01 \mathrm{~V}$.

In order to clarify the reactivity of $\mathrm{H}_{2} @ \mathrm{C}_{60}$, the solid-state mechanochemical $[2+2]$ dimerization reaction (23) was conducted. A mixture of $\mathrm{H}_{2} @ \mathrm{C}_{60}$ and 1 molar equivalent of 4-aminopyridine as the catalyst
(24) was vigorously shaken by the use of a high-speed vibration mill for 30 min under $\mathrm{N}_{2}$ according to our previous procedure $(23,24)$. The ${ }^{1} \mathrm{H}$ NMR spectrum of the product mixture exhibited a signal at $\delta=-4.04 \mathrm{ppm}$ of the [2+2] dimer, $\left(\mathrm{H}_{2} @ \mathrm{C}_{60}\right)_{2}$, and a signal of unchanged $\mathrm{H}_{2} @ \mathrm{C}_{60}$ at $\delta=-1.44$ ppm, in an integrated ratio of 3:7. This result indicates that the dumbbell-shaped dimer of $\mathrm{H}_{2} @ \mathrm{C}_{60}$ is formed in the same yield as that for the reaction of empty $\mathrm{C}_{60}$ (24) (Fig. 4). No effect of the encapsulated $\mathrm{H}_{2}$ was observed upon reactivity of the $\mathrm{C}_{60}$ cage. The extent of the upfield shift of the ${ }^{1} \mathrm{H}$ NMR signal (2.60 ppm) observed for the dimer $\left(\mathrm{H}_{2} @ \mathrm{C}_{60}\right)_{2}$ was similar to that observed upon the same dimerization reaction in ${ }^{3} \mathrm{He}$ NMR (2.52 ppm) (24) for ${ }^{3} \mathrm{He}$ encapsulated in the ratio of $\sim 0.1 \%$ in $\mathrm{C}_{60}(9,10)$.

The endohedral fullerene $\mathrm{H}_{2} @ \mathrm{C}_{60}$ is nearly as stable as $\mathrm{C}_{60}$ itself. For example, the encapsulated $\mathrm{H}_{2}$ does not escape even when heated at $500^{\circ} \mathrm{C}$ for $10 \mathrm{~min}$. Thus, $\mathrm{H}_{2} @ \mathrm{C}_{60}$ can be viewed as a stable hydrocarbon molecule that has neither $\mathrm{C}-\mathrm{H}$ covalent bonds nor $\mathrm{C} \cdot \bullet \mathrm{H}$ interactions. It is likely that our method could be used to synthesize endohedral fullerenes such as $\mathrm{D}_{2} @ \mathrm{C}_{60}$ and $\mathrm{HD} @ \mathrm{C}_{60}$, as well as the homologous series with $\mathrm{C}_{70}$. Our work here complements the total chemical synthesis of $\mathrm{C}_{60}$ recently achieved by Scott and co-workers (25) and implies that organic synthesis can be a powerful means for the production of yet unknown classes of endohedral fullerenes.

\section{References and Notes}

1. T. Akasaka, S. Nagase, Eds., Endofullerenes: A New Family of Carbon Clusters (Kluwer, Dordrecht, 2002).

2. H. Shinohara, in Fullerenes: Chemistry, Physics and Technology, K. M. Kadish, R. S. Ruoff, Eds. (Wiley, New York, 2000), pp. 357-393.
3. H. Shinohara, Rep. Prog. Phys. 63, 843 (2000)

4. S. Liu, S. Sun, J. Organomet. Chem. 599, 74 (2000).

5. S. Nagase, K. Kobayashi, T. Akasaka, Bull. Chem. Soc. Jpn. 69, 2131 (1996).

6. D. S. Bethune et al., Nature 366, 123 (1993).

7. S. Kobayashi et al., J. Am. Chem. Soc. 125, 8116 (2003).

8. H. Kato et al., J. Am. Chem. Soc. 125, 4391 (2003).

9. M. Saunders, R. J. Cross, H. A. Jiménez-Vázquez, R. Shimshi, A. Khong, Science 271, 1693 (1996).

10. M. Saunders et al., Nature 367, 256 (1994).

11. R. J. Cross, A. Khong, M. Saunders, J. Org. Chem. 68 , 8281 (2003).

12. M. S. Syamala, R. J. Cross, M. Saunders, J. Am. Chem. Soc. 124, 6216 (2002).

13. K. Yamamoto et al., J. Am. Chem. Soc. 121, 1591 (1999).

14. M. Saunders et al., J. Am. Chem. Soc. 116, 2193 (1994).

15. Y. Rubin et al., Angew. Chem. Int. Ed. Engl. 40, 1543 (2001).

16. Y. Rubin, Top. Curr. Chem. 199, 67 (1999).

17. G. Schick, T. Jarrosson, Y. Rubin, Angew. Chem. Int Ed. Engl. 38, 2360 (1999).

18. Y. Murata, M. Murata, K. Komatsu, Chem. Eur. J. 9 1600 (2003)

19. Y. Murata, M. Murata, K. Komatsu, J. Am. Chem. Soc. 125, 7152 (2003).

20. Materials and methods are available as supporting material on Science Online.

21. J. E. McMurry, Chem. Rev. 89, 1513 (1989).

22. M. Rüttimann et al., Chem. Eur. J. 3, 1071 (1997)

23. G.-W. Wang, K. Komatsu, Y. Murata, M. Shiro, Nature 387, 583 (1997).

24. K. Komatsu et al., J. Org. Chem. 63, 9358 (1998).

25. L. T. Scott et al., Science 295, 1500 (2002).

26. Supported by a Grant-in-Aid for Center of Excellence Research on Elements Science (no. 12CE2005) and by a Grant-in-Aid for Creative Scientific Research Collaboratory on Electron Correlation Toward a New Research Network Between Physics and Chemistry (no. 13NP0201), both from the Ministry of Education, Culture, Sports, Science, and Technology, Japan.

\section{Supporting Online Material}

www.sciencemag.org/cgi/content/full/307/5707/238/ DC1

Materials and Methods

Figs. S1 to S9

References

8 October 2004; accepted 23 November 2004 10.1126/science. 1106185

\title{
Corrected Late Triassic Latitudes for Continents Adjacent to the North Atlantic
}

\author{
Dennis V. Kent ${ }^{1,2 *}$ and Lisa Tauxe ${ }^{3}$
}

\begin{abstract}
We use a method based on a statistical geomagnetic field model to recognize and correct for inclination error in sedimentary rocks from early Mesozoic rift basins in North America, Greenland, and Europe. The congruence of the corrected sedimentary results and independent data from igneous rocks on a regional scale indicates that a geocentric axial dipole field operated in the Late Triassic. The corrected paleolatitudes indicate a faster poleward drift of $\sim 0.6$ degrees per million years for this part of Pangea and suggest that the equatorial humid belt in the Late Triassic was about as wide as it is today.
\end{abstract}

Paleomagnetism is used to determine ancient latitude, but its reliability depends on two assumptions: (i) that the time-averaged geomagnetic field is closely approximated by that of a geocentric axial dipole (GAD), and (ii) that there is no systematic bias in how the geomagnetic field is imprinted in rocks. Although the GAD hypothesis ( 1 ) is supported by paleomagnetic data for the past few million years $(2,3)$, departures from the GAD model 
have been invoked to explain anomalously shallow directions observed in some older rocks (4-6). On the other hand, a shallow bias or inclination error (7) has been found in laboratory redeposition experiments and in some modern natural sediments (8). A good example of the ambiguity in distinguishing between a non-GAD field and recorder bias is

${ }^{1}$ Department of Geological Sciences, Rutgers University, Piscataway, NJ 08854, USA. 'Lamont-Doherty Earth Observatory of Columbia University (LDEO), Palisades, NY 10964, USA. ${ }^{3}$ Scripps Institution of Oceanography, La Jolla, CA 92093, USA.

*To whom correspondence should be addressed. E-mail: dvk@rci.rutgers.edu found in the paleomagnetic record from continental basins that developed during rifting of the Pangea supercontinent in the early Mesozoic and are now distributed along the margins of the North Atlantic (Fig. 1). One of the largest and best studied of the rift basins is the Newark basin in eastern North America, where more than $5000 \mathrm{~m}$ of strata (mainly continental redbeds) were recovered in scientific drilling (9) and which yielded a 35 million year (My)-long record of latitudinal drift calibrated by an astronomically tuned geomagnetic polarity time scale $(10,11)$. The average paleomagnetic inclinations from the Dan River basin (12) and the Fundy basin (13) indicate low paleolatitudes that are consistent with the Newark basin data. However, paleomagnetic directions from the more distant Jameson Land basin in Greenland (Fig. 1) are anomalously shallow and imply a paleolatitude $\sim 10^{\circ}$ lower than predicted from coeval sections in North America (14). This discrepancy is too large to be explained by uncertainties in the reconstruction of Greenland to North America $(15,16)$. Therefore, either the magnetizations of the sedimentary rocks are biased by inclination error or the Late Triassic time-averaged field included large nondipole (axial octupole) contributions (4).

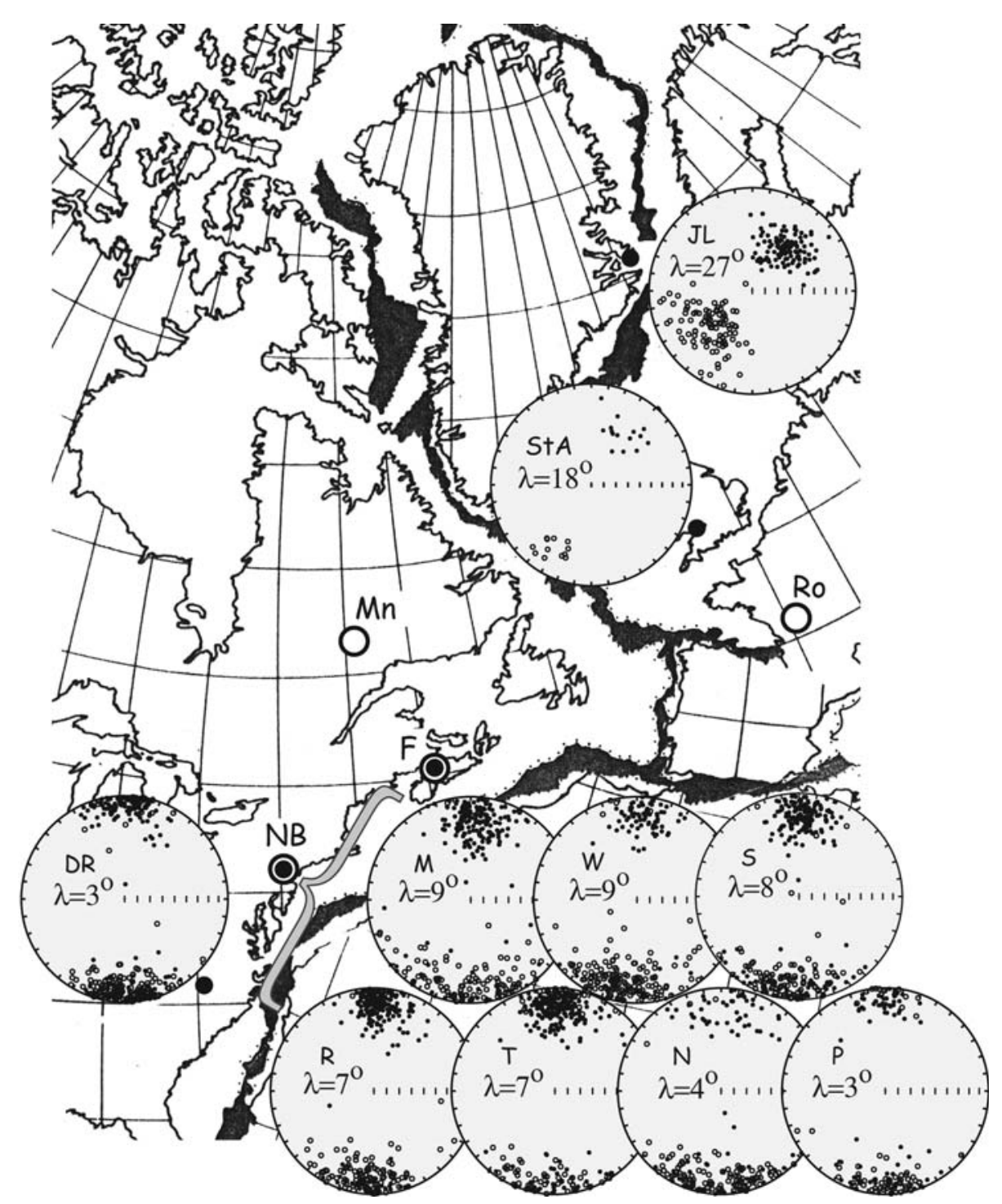

Fig. 1. Paleomagnetic sampling localities of key Late Triassic and earliest Jurassic sedimentary and igneous rock units plotted on a Pangea reconstruction (16). For reference, present-day latitude/ longitude grids $\left(5^{\circ}\right.$ by $\left.5^{\circ}\right)$ are shown for each continent. Insets give the paleomagnetic direction data (solid and open symbols are on the lower and upper hemisphere, respectively, of equal-area projections) and the implied paleolatitudes $(\lambda)$ from each section: DR, Dan River basin (12); NB, Newark basin with data from seven drill cores labeled with the first initial of the drill core (M, W, S, R, T, N, and P) (Table 1) (10); JL, Jameson Land basin (14); StA, St. Audrie's Bay section (19). Other data discussed in the text are from $\mathrm{F}$, the Fundy basin $(13,22) ; \mathrm{Mn}$, the Manicouagan impact structure $(24,25)$; and Ro, the Rochechouart impact structure (23). The data are summarized in Table 1.
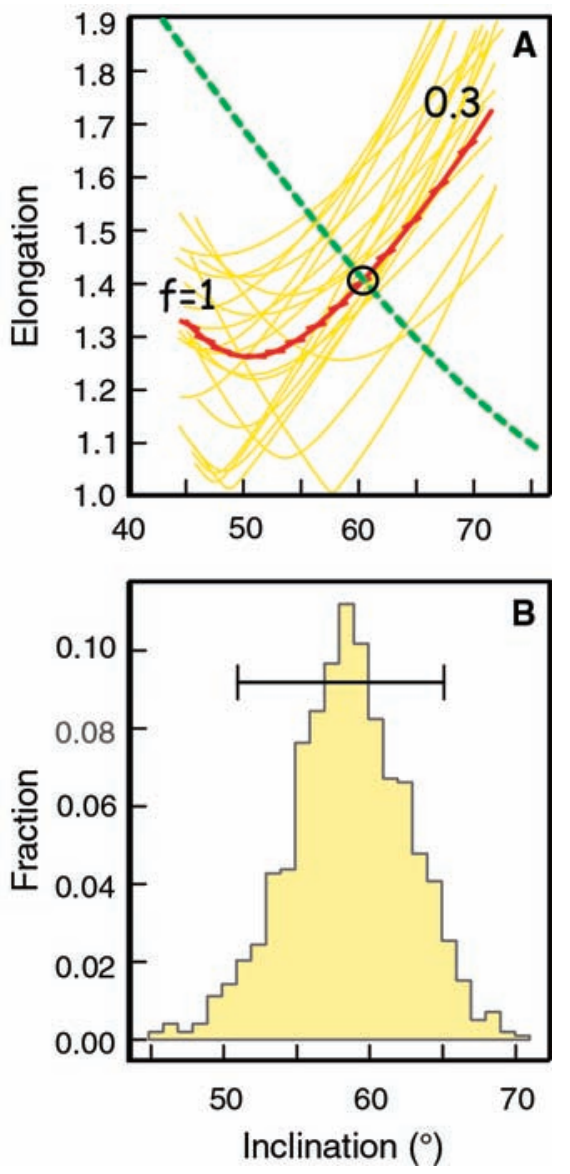

Fig. 2. E/l analysis of sample characteristic magnetization directions from Fleming Fjord Formation, Jameson Land, Greenland (12). (A) The trajectory (solid red line) of mean inclination versus elongation calculated for the Jameson Land data shown in the inset to Fig. 1, as the data are inverted with values for $f$ ranging from 0.3 to 1.0. Yellow lines are examples of bootstrapped trajectories. The predicted $E / I$ trend with latitude of the TK03.GAD model (17) is shown as the blue dashed line; the E/I of the data consistent with the model is circled. (B) A histogram of 1000 bootstrapped intersections of the kind shown in (A) from bootstrapped curves. The 95\% confidence bounds on the corrected inclination are also shown (Table 1). 


\section{R E P O R T S}

To address this problem, we employed a method to recognize and correct for inclination error that is based on a statistical geomagnetic field model (TK03.GAD) (17) consistent with global paleomagnetic data from lavas for the past $5 \mathrm{My}$. The model treats the geomagnetic field as the sum of the axial dipole component with a nonzero mean plus the nonaxial dipole contributions and higher order terms with means of zero. Each of the terms is drawn from normal distributions, the variance of which depends in a simple way on degree and order. This is similar to Constable and Parker's Giant Gaussian approach to paleosecular variation modeling (18). Like all GAD models, TK03.GAD predicts that the mean field inclination, $I$, is a function of latitude, $\lambda$ :

$$
\tan I=2 \tan \lambda
$$

The model also predicts that secular variation will result in a distribution of virtual geomagnetic poles that is essentially circular at any observation site. This implies that the distribution of directions (declination and inclination) will be increasingly elongate as the observation site latitude decreases from the pole(s) to the equator. Accordingly, the model predicts a unique elongation/inclination (E/I) relationship for directional distributions. If the directions were affected by inclination error (either during deposition or imparted by compaction), the observed inclination, $I_{\mathrm{o}}$, will be related to the ambient field inclination, $I_{\mathrm{f}}$, by

$$
\tan I_{\mathrm{o}}=f \tan I_{\mathrm{f}}
$$

where $f$ is the flattening factor (7). Inclination error affects the distribution of directions by increasing the east-west elongation while decreasing inclination. A nonzero axial octupole contribution of the same sign as the axial dipole will also decrease inclination, but it will increase elongation in the up-down plane. Hence, the two mechanisms, each capable of producing shallow inclinations, have different effects on the distribution of directions. If inclination error is the cause of the shallow bias, the data can be inverted, with the inverse of Eq. 2 searching for a value of $f$ that yields an elongation and inclination combination consistent with the field model; the corrected mean inclination should provide a more accurate estimate of latitude according to Eq. 1. The hypothesis that the statistical properties of the geomagnetic field in remote epochs were similar to those of the more recent [0 to $5 \mathrm{My}$ ago (Ma)] geomagnetic field can be tested for the Late Triassic by the ability of the E/I method to produce an internally consistent latitudinal framework.

We analyzed characteristic directions from Jameson Land that were isolated by progressive thermal demagnetization in 222 samples, which include data for 150 samples reported previously (14) and 72 additional samples collected in a subsequent field season (Fig. 1 and Table 1). The overall mean direction (after small bedding tilt corrections and inverting to common polarity) was a declination $(D)$ of $43.1^{\circ}$, with $I$ of $45.1^{\circ}$, similar to the original subset of 150 samples $\left(D=43.6^{\circ}, I=45.3^{\circ}\right)$. The distribution of directions is elongated eastwest, which points to inclination error in producing the anomalously shallow mean inclination (Fig. 2). The data set was inverted with values of $f$ from 0.3 to 1.0 . For each value of $f$, we calculated the elongation and mean inclination of the distribution (17). The evolution of E/I with $f$ (Fig. 2A) crosses the curve predicted by the TK03.GAD model at $I=60^{\circ}$ for $f=0.58$. Bootstrap resampling of the data yielded 1000 crossings (Fig. 2B) and 95\% confidence bounds of 51 to $65^{\circ}$. Therefore, results of the $\mathrm{E} / \mathrm{I}$ analysis indicate a direction that is $\sim 15^{\circ}$ steeper than the initial mean inclination (Table 1). Results of E/I analysis on data from the Dan River basin (12) and from the seven drill cores from the Newark basin (10) (fig. S1) give distributions (each based on 148 to 336 samples) that are elongated eastwest, consistent with inclination error; bestfit $f$ values range from 0.40 to 0.66 (Table 1).

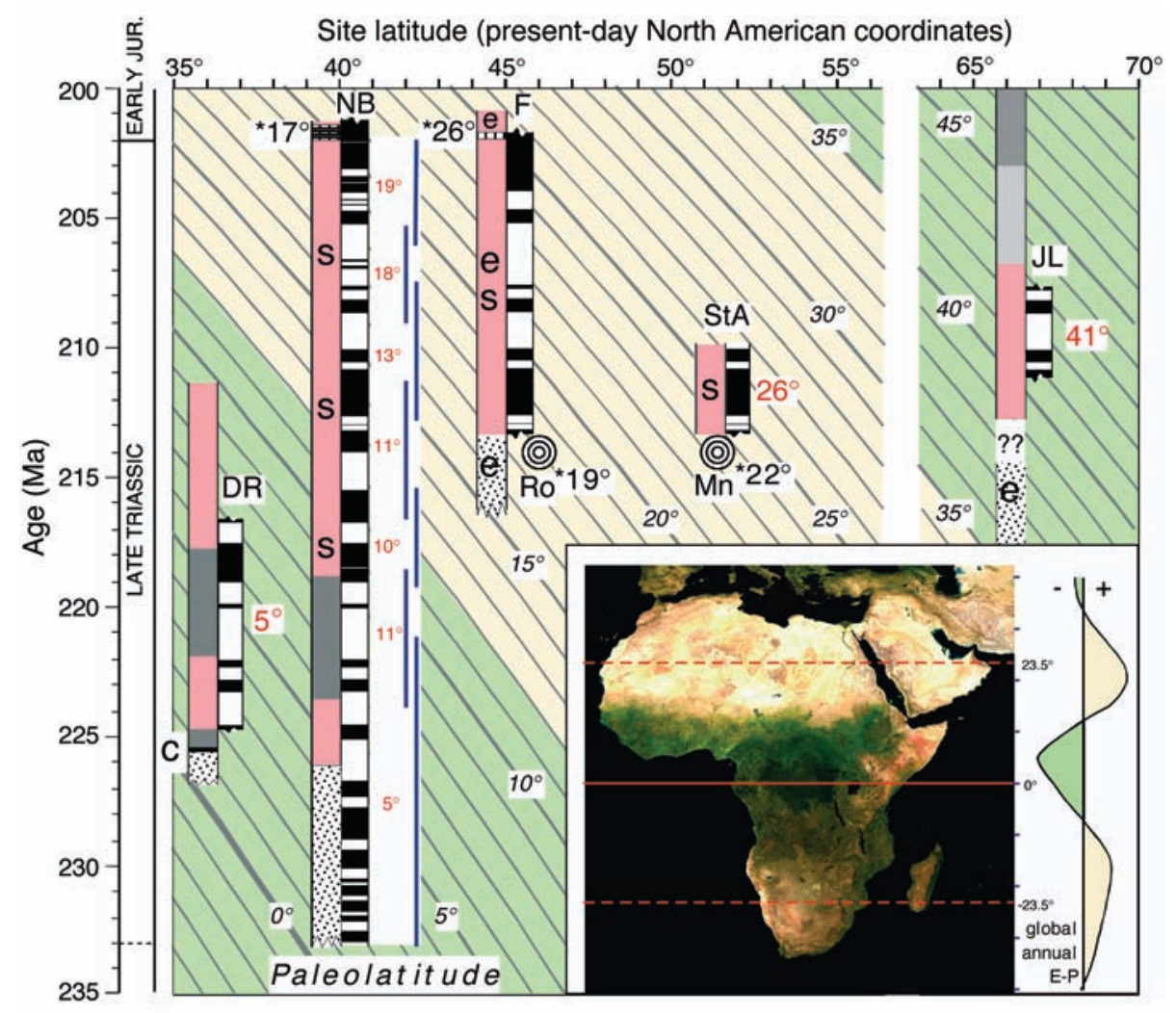

Fig. 3. Paleolatitude nomogram for the Late Triassic and earliest Jurassic of a portion of Pangea. Paleolatitude contours are based on a smoothed progression of latitudes that are calculated from corrected mean inclinations, according to the E/I method, from seven drill cores from the Newark basin (NB, with corrected paleolatitudes adjacent to solid lines indicating the age ranges of the cores) and take into account present geographic relationships. Mean paleomagnetic declinations for the Late Triassic of eastern America are typically within a few degrees of north-south (Table 1), and hence differences in present-day latitudes of the sites in North American coordinates closely approximate differences in paleolatitude. Site latitudes for the Jameson Land (JL) section in Greenland (14), the St. Audrie's Bay (StA) section (19), and the 214-My-old (27) Rochechouart impact structure (Ro) (23) in Europe were transferred to North American coordinates according to reconstruction parameters from Bullard et al. (16) (Table 1). The geomagnetic polarity time scale from the NB cores (11) was used as the basis of magnetostratigraphic correlation (solid and open bars denote normal and reverse polarity, respectively) and age control. Mean paleolatitudes from corrected inclinations are indicated for $\mathrm{JL}$, StA, and the Dan River basin (DR) (Table 1). Paleolatitudes with asterisks are for igneous rocks from earliest Jurassic ( $\sim 200 \mathrm{Ma})$ Central Atlantic Magmatic Province lavas in the NB (21) and Fundy (F) basins (22) and from the 214-Myold (26) Manicouagan $(\mathrm{Mn})$ impact structure in Quebec $(24,25)$ and Ro. Climate lithofacies are shown for the DR, NB, and F (35) and JL (37) sections where $c$ is coal, $s$ is saline minerals, and e is eolian deposits; light to dark shading in lithology columns ranges from fine-grained redbeds to black shales, with stippling indicating sandstones. The inset is (left) a Landsat image of Africa (44) and (right) the global zonal mean profile of evaporation minus precipitation (E-P) (45). Green and yellow colors indicate more humid and arid conditions, respectively, the present-day latitudinal ranges of which are shown on the paleolatitude nomogram for comparison. 
Although the data set from St. Audrie's Bay in Somerset, United Kingdom, is rather small (27 sites), the results are included because they are possibly the first for the Late Triassic of Europe to be supported by modern demagnetization techniques and the sitemean directions are available (19).

We compared the corrected results, which differ in age as well as location, by constructing a paleolatitude versus age nomogram (13) by fitting a second-order polynomial curve to the corrected paleolatitude versus age progression determined from the Newark basin cores (Table 1). We then used that relationship to predict paleolatitudes over the same 35-My interval for tectonically contiguous or reconstructed areas. The corrections for inclination error bring the paleolatitude data for the Triassic basins into agreement (Fig. 3). In particular, the corrected paleolatitude for the previously discrepant result from Jameson Land is now consistent with the paleolatitude predicted from the corrected Newark basin data. The data set from St. Audrie's Bay also falls into line after correction.

As an independent check on the validity of the corrections for inclination error, we can use paleomagnetic data from approximately coeval igneous rock units, which are not subject to inclination error. Lava flows of the Central Atlantic Magmatic Province of the earliest ( $200 \mathrm{Ma})$ Jurassic age (20) occur in several of the rift basins in eastern North America. For comparison with the Newark basin sedimentary results, we used a compilation of the most reliable data as determined by Prevot and McWilliams (21) for the three major extrusive units in the
Newark and nearby Hartford basins. These lava flow data indicate a paleolatitude of $17 \pm$ $5^{\circ}$ for the Newark basin (Table 1), which is in much better agreement with the paleolatitude after correction for inclination error $\left(19^{\circ}\right)$ than without correction $\left(\sim 9^{\circ}\right)$, as determined from the immediately underlying (Upper Triassic and lowermost Jurassic) sedimentary rocks of the Passaic Formation in the Newark basin Martinsville core (Fig. 3 and Table 1). Paleomagnetic results from the Upper Triassic and lowermost Jurassic Blomidon Formation in the Fundy basin (13) give an anomalously low paleolatitude $\left(\sim 12^{\circ}\right)$, but these inclinationonly sedimentary data could not be tested or corrected with the E/I method. Nevertheless, paleomagnetic data (22) for the overlying North Mountain Basalt indicate a paleolatitude of $26^{\circ}$, which is consistent with the paleolatitude predicted from the corrected Newark data (Fig. 3). Paleolatitudes from two older igneous rock units also agree with the paleolatitudeage matrix predicted from the corrected Newark basin data (Fig. 3): Rochechouart (23) in France and Manicouagan $(24,25)$ in Quebec, which are impact structures dated at $\sim 214$ Ma $(26,27)$.

With the caveat that these igneous rocks may not adequately average secular variation because of the paucity of cooling units, the overall agreement of the igneous data with the predictions based on the E/I method supports the hypothesis that inclination error pervasively affects the sedimentary rocks we studied. An early study that found no substantial difference in paleomagnetic directions, all of normal polarity, from sediments and igneous rocks in the Newark basin (28) was before routine use of progressive thermal demagnetization, which has revealed that a depositional component of normal and reverse polarity with shallow directions in these redbeds is typically masked by a steeper normal polarity thermochemical overprint (29). On the other hand, an early-noticed (30) discordance in presumed Triassic latitudes between North America and Europe in a Pangea configuration is likely to be an artifact of age differences and inclination error, because it was largely based on a comparison between data from Jurassic igneous rock units in eastern North America and Triassic sedimentary rocks in western Europe. The corrected St. Audrie's Bay data show that Late Triassic latitudes of Europe are consistent with those of North America in a Pangea (16) fit.

Slow poleward motion of $\sim 0.3^{\circ}$ per My for North America was inferred from the original Newark basin paleomagnetic data (10), but these are biased by inclination error, which underestimates paleolatitudinal change. The corrected inclinations indicate a much faster rate of poleward motion of $\sim 0.6^{\circ}$ per My from $\sim 235$ to 200 Ma, which emphasizes the need for precise spatiotemporal registry of climate-sensitive lithofacies in paleoclimate studies. The overall distribution of such facies within the cyclic successions suggests that generally moist conditions extended from the coal-bearing and black shale units in the Dan River basin (31) near the paleoequator and black shales of the Lockatong Formation in the Newark basin at 5 to $10^{\circ}$ to where eolian deposits in the Fundy basin (32) are encountered at $\sim 15^{\circ}$ paleolatitude. The width of the equa-
Table 1. Summary of paleomagnetic data from Late Triassic and earliest Jurassic rocks. Slat and Slon are the latitude and longitude of the sampling localities; entries in parentheses are site locations in Greenland and Europe transferred to North American coordinates according to Bullard et al. (16). Age is the mean age of the sampled rocks; $n$ is the number of data included in the mean values; $D$ and $/$ are the mean declination and mean inclination of the characteristic magnetization data; $\lambda$ is paleolatitude calculated from the mean inclination; $f$ is the flattening factor determined from E/I analysis, $l^{\prime}$ is the corrected mean inclination and $\pm l^{\prime}$ is its $95 \%$ confidence interval; $\lambda^{\prime}$ is the corresponding corrected paleolatitude and $\pm \lambda^{\prime}$ its $95 \%$ confidence interval; and Ref. is the literature source for the age and paleomagnetic data.

\begin{tabular}{|c|c|c|c|c|c|c|c|c|c|c|c|c|c|}
\hline Locality & Slat $\left({ }^{\circ} N\right)$ & Slon $\left({ }^{\circ} \mathrm{E}\right)$ & Age (Ma) & $n$ & $D\left({ }^{\circ}\right)$ & $\left.I^{\circ}\right)$ & $\lambda\left({ }^{\circ} \mathrm{N}\right)$ & $f$ & $I^{\prime}\left({ }^{\circ}\right)$ & $\pm I^{\prime}\left({ }^{\circ}\right)$ & $\lambda^{\prime}\left({ }^{\circ} \mathrm{N}\right)$ & $\pm \lambda^{\prime}\left({ }^{\circ} N\right)$ & Ref. \\
\hline \multicolumn{14}{|c|}{ Sedimentary } \\
\hline Dan River & 36.5 & -79.5 & 221 & 333 & 0.5 & 5.9 & 3.0 & 0.59 & 10 & $8-12$ & 5.0 & $4.0-6.1$ & (12) \\
\hline \multicolumn{14}{|l|}{ Newark basin } \\
\hline Princeton & 40.4 & -74.6 & 227 & 148 & 0.1 & 5.2 & 2.6 & 0.56 & 9 & $5-13$ & 4.5 & $2.5-6.6$ & (10) \\
\hline Nursery & 40.3 & -74.8 & 221 & 194 & 1.8 & 8.8 & 4.4 & 0.40 & 21 & $16-25$ & 10.9 & $8.2-13.1$ & " \\
\hline Titusville & 40.3 & -74.9 & 217 & 308 & 2.9 & 13.0 & 6.6 & 0.63 & 20 & $17-23$ & 10.3 & $8.7-12.0$ & $"$ \\
\hline Rutgers & 40.5 & -74.4 & 214 & 336 & 4.3 & 14.2 & 7.2 & 0.66 & 21 & $19-24$ & 10.9 & $9.8-12.6$ & " \\
\hline Somerset & 40.5 & -74.6 & 211 & 309 & 4.9 & 15.7 & 8.0 & 0.63 & 24 & $21-28$ & 12.6 & $10.9-14.9$ & $"$ \\
\hline Weston & 40.2 & -74.6 & 207 & 246 & 7.4 & 17.5 & 8.9 & 0.49 & 33 & $28-37$ & 18.0 & $14.9-20.6$ & $"$ \\
\hline Martinsville & 40.6 & -74.6 & 204 & 302 & 3.8 & 18.2 & 9.3 & 0.49 & 34 & $29-38$ & 18.6 & $15.5-21.3$ & $"$ \\
\hline St. Audrie's Bay & $\begin{array}{c}51.2 \\
(51.9)\end{array}$ & $\begin{array}{c}-3.3 \\
(-40.5)\end{array}$ & 212 & 27 & 31.6 & 33.4 & 18.2 & 0.66 & 44 & $33-48$ & 25.8 & $18.0-29.0$ & (19) \\
\hline \multirow[t]{2}{*}{ Jameson Land } & $\begin{array}{c}71.5 \\
(66.2)\end{array}$ & $\begin{array}{l}-22.7 \\
(-35.3)\end{array}$ & 209 & 222 & 43.1 & 45.1 & 26.6 & 0.58 & 60 & $51-65$ & 40.9 & $31.7-47.0$ & (14) \\
\hline & & & \multicolumn{11}{|c|}{ Igneous } \\
\hline Newark & 40.5 & -74.5 & 201 & 3 & 3.5 & 31.4 & $17.0 \pm 5.0$ & - & - & - & - & - & $(21)$ \\
\hline North Mountain & 45.0 & -65.0 & 201 & 9 & 17.7 & 44.5 & $26.2 \pm 8.6$ & - & - & - & - & - & (22) \\
\hline Manicouagan & 51.4 & -68.6 & 214 & 11 & 11.8 & 38.3 & $21.6 \pm 5.8$ & - & - & - & - & - & $(24-26)$ \\
\hline Rochechouart & $\begin{array}{c}45.8 \\
(46.5)\end{array}$ & $\begin{array}{c}+0.8 \\
(-36.5)\end{array}$ & 214 & 33 & 226.4 & -34.8 & $19.2 \pm 2.6$ & - & - & - & - & - & $(23,27)$ \\
\hline
\end{tabular}




\section{R E P O R T S}

torial humid belt in the Late Triassic was comparable to today's (Fig. 3), a conclusion that contrasts with some previous suggestions of a much more restricted or even dry equatorial belt in the Triassic $(33,34)$. Poleward motion can explain the generally drier northward and up-section facies pattern in the Mesozoic rift basins of eastern North America $(32,35)$ as this part of Pangea drifted out of the equatorial humid belt. At the same time, the up-section progression to more humid facies in the Fleming Fjord Formation $(36,37)$ and the overlying plant-bearing Kap Stewart Formation of latest Triassic and earliest Jurassic age (38) in the Jameson Land basin would reflect the drift of this area into the temperate humid belt.

We conclude that the congruence of the corrected paleomagnetic data from sedimentary rocks and independent data from igneous rocks ranging over thousands of kilometers and tens of millions of years indicates that a GAD field similar to that of the past $5 \mathrm{My}$ was operative at least $200 \mathrm{Ma}$ in the Late Triassic and earliest Jurassic. In particular, we see no evidence for a major octupole contribution in either the shapes of the distributions of directions in the sedimentary units or in the geographic distribution of site paleolatitudes. As indicated by other recent studies $(17,39-41)$, there is thus little empirical basis to invoke persistent departures from the GAD field, especially zonal octupole contributions, to address tectonic problems (4, 42, 43). Instead, our results suggest that inclination error in sedimentary rocks may be more prevalent than has been supposed, perhaps especially in cases where the magnetizations that have been isolated are most likely to represent a depositional remanence carried by hematite. The success of the E/I method (17) to determine the degree of flattening and to correct any bias in inclinations from the distribution of directions should provide motivation for more intensive sampling of sedimentary rock units and for making detailed data more accessible.

\section{References and Notes}

1. J. Hospers, Nature 173, 1183 (1954).

2. C. L. Johnson, C. G. Constable, Geophys. J. Int. 131, 643 (1997).

3. R. T. Merrill, P. L. McFadden, Phys. Earth Planet. Inter. 139, 171 (2003).

4. R. Van der Voo, T. H. Torsvik, Earth Planet. Sci. Lett. 187, 71 (2001)

5. J. Si, R. Van der Voo, Terra Nova 13, 471 (2001).

6. M. Westphal, Earth Planet. Sci. Lett. 117, 15 (1993).

7. R. F. King, Mon. Not. R. Astron. Soc. Geophys. Suppl. 7, 115 (1955).

8. L. Tauxe, D. V. Kent, Geophys. J. R. Astron. Soc. 77, $543(1984)$

9. P. Olsen, D. V. Kent, B. Cornet, W. K. Witte, R. W. Schlische, Geol. Soc. Am. Bull. 108, 40 (1996).

10. D. V. Kent, P. E. Olsen, W. K. Witte, J. Geophys. Res. 100, 14 (1995)

11. D. V. Kent, P. E. Olsen, J. Geophys. Res. 104, 12 (1999).

12. D. V. Kent, P. E. Olsen, Geol. Soc. Am. Bull. 109, 366 (1997).

13. D. V. Kent, P. E. Olsen, Earth Planet. Sci. Lett. 179, $311(2000)$
14. D. V. Kent, L. B. Clemmensen, Bull. Geol. Soc. Den. 42, 121 (1996).

15. W. R. Roest, S. P. Srivastava, Geology 17, 1000 (1989).

16. E. C. Bullard, J. E. Everett, A. G. Smith, Philos. Trans. R. Soc. London Ser. A 258, 41 (1965).

17. L. Tauxe, D. V. Kent, Geophys. Monogr. Am. Geophys. Union 145, 101 (2004).

18. C. G. Constable, R. L. Parker, J. Geophys. Res. 93, 11 (1988).

19. J. C. Briden, B. A. Daniels, J. Geol. Soc. London 156 317 (1999).

20. A. Marzoli et al., Science 284, 616 (1999).

21. M. Prevot, M. McWilliams, Geology 17, 1007 (1989).

22. J. P. Hodych, A. Hayatsu, Can. J. Earth Sci. 25, 1972 (1988).

23. J. Pohl, H. Soffel, Zeitschrift fur Geophysik 37, 857 (1971).

24. W. A. Robertson, Can. J. Earth Sci. 4, 641 (1967).

25. A. Larochelle, K. L. Currie, J. Geophys. Res. 72, 4163 (1967).

26. J. P. Hodych, G. R. Dunning, Geology 20, 51 (1992).

27. S. P. Kelley, J. G. Spray, Meteorit. Planet. Sci. 32, 629 (1997).

28. N. D. Opdyke, J. Geophys. Res. 66, 1941 (1961).

29. W. K. Witte, D. V. Kent, J. Geophys. Res. 96, 19 (1991).

30. J. L. Roy, Earth Planet. Sci. Lett. 14, 103 (1972).

31. E. I. Robbins, G. P. Wilkes, D. A. Textoris, in Triassic-Jurassic Rifting: North America and Africa, W. Manspeizer, Ed. (Elsevier, Amsterdam, 1988), pp. 649-682.

32. J. F. Hubert, K. A. Mertz, Geology 8, 516 (1980).

33. K. M. Wilson, D. Pollard, W. W. Hay, S. L. Thompson, C. N. Wold, Geol. Soc. Am. Spec. Pap. 288, 91 (1994).

34. J. T. Parrish, Journal of Geology 101, 215 (1993).
35. J. P. Smoot, Palaeogeogr. Palaeoclimatol. Palaeoecol. 84, 369 (1991).

36. L. B. Clemmensen, D. V. Kent, F. A. Jenkins Jr. Palaeogeogr. Palaeoclimatol. Palaeoecol. 140, 135 (1998).

37. L. B. Clemmensen, Geol. Surv. Greenland Bull. 136, 5 (1980).

38. J. C. McElwain, D. J. Beerling, F. I. Woodward, Science 285, 1386 (1999).

39. G. Muttoni et al., Earth Planet. Sci. Lett. 215, 379 (2003).

40. S. Gilder et al., Earth Planet. Sci. Lett. 206, 587 (2003).

41. W. Krijgsman, L. Tauxe, Earth Planet. Sci. Lett. 222, 685 (2004).

42. T. H. Torsvik, R. Van der Voo, Geophys. J. Int. 151, 771 (2002).

43. P. Rochette, D. Vandamme, Ann. Geofis. 44, 649 (2001)

44. NASA, Visible Earth, available at http://visibleearth. nasa.gov/.

45. T. J. Crowley, G. R. North, Oxford Monogr. Geol. Geophys. 18 (1991).

46. We thank $P$. Olsen for many discussions of the Triassic-Jurassic world and the reviewers for insightful comments. Supported by National Science Foundation grant nos. EAR-0310240 (D.V.K.) and EAR-0003395 (L.T.). This is LDEO contribution \#6700.

\section{Supporting Online Material}

www.sciencemag.org/cgi/content/full/307/5707/240/ DC1

Fig. S1

References and Notes

29 September 2004; accepted 9 December 2004 $10.1126 /$ science. 1105826

\title{
An Astronomical $2175 \AA$ Å Feature in Interplanetary Dust Particles
}

\author{
John Bradley, ${ }^{1 *}$ Zu Rong Dai, ${ }^{1}$ Rolf Erni, ${ }^{2}$ Nigel Browning, \\ Giles Graham, ${ }^{1}$ Peter Weber, ${ }^{1}$ Julie Smith, ${ }^{1}$ lan Hutcheon, ${ }^{1}$ \\ Hope Ishii, ${ }^{1}$ Sasa Bajt, ${ }^{1}$ Christine Floss, ${ }^{4}$ Frank Stadermann, ${ }^{4}$ \\ Scott Sandford ${ }^{5}$
}

\begin{abstract}
The 2175 angstrom extinction feature is the strongest (visible-ultraviolet) spectral signature of dust in the interstellar medium. Forty years after its discovery, the origin of the feature and the nature of the carrier(s) remain controversial. Using a transmission electron microscope, we detected a 5.7electron volt (2175 angstrom) feature in interstellar grains embedded within interplanetary dust particles (IDPs). The carriers are organic carbon and amorphous silicates that are abundant in IDPs and in the interstellar medium. These multiple carriers may explain the enigmatic invariant central wavelength and variable bandwidth of the astronomical 2175 angstrom feature.
\end{abstract}

Much of what is known about grains in space comes from spectral features observed in emission, polarization, and absorption (1-7). The $2175 \AA$ peak is by far the strongest feature observed in the ultraviolet (UV)-

\begin{abstract}
${ }^{1}$ Institute of Geophysics and Planetary Physics, Lawrence Livermore National Laboratory, Livermore, CA 94550, USA. ${ }^{2}$ Department of Chemical Engineering, University of California at Davis, CA 95616, USA. ${ }^{3}$ National Center for Electron Microscopy, Lawrence Berkeley National Laboratory, Berkeley, CA 94720, USA. ${ }^{4}$ Laboratory for Space Sciences, Washington University, St. Louis, MO 63130, USA. ${ }^{5}$ Astrophysics Branch, NASA-Ames Research Center, Moffett Field, CA 94035, USA.
\end{abstract}

*To whom correspondence should be addressed. E-mail: jbradley@igpp.ucllnl.org visible wavelength range along most lines of sight for which it can be measured (Fig. 1, A and B) (4-7). The feature is enigmatic: Its central wavelength is almost invariant, but its bandwidth varies from one line of sight to another, suggesting multiple carriers or a single carrier with variable properties. From interstellar abundances of the elements and typical UV transition strengths, the carrier is either oxygen-rich (e.g., oxides or silicates) or carbon-rich (e.g., graphite or organic compounds) $(1-4,8)$. We searched UV spectra of chondritic IDPs for an extinction feature near the $\sim 2175 \AA$ interstellar feature (Fig. 1). Materials similar to the two most abundant grain types seen in the 